\title{
EPITAXIAL GROWTH OF III-NITRIDE LAYERS \\ ON ALUMINUM NITRIDE SUBSTRATES
}

\author{
L.J. Schowalter, ${ }^{*}+$ Y. Shusterman, ${ }^{*}$ R. Wang, ${ }^{*}$ I. Bhat, ${ }^{*}$ G. Arunmozhi, ${ }^{*}$ and G.A. Slack ${ }^{*, \dagger}$ \\ *Physics, Appl. Physics, \& Astronomy Dept., Rensselaer Polytechnic Inst., \\ Troy, NY 12180, schowl@rpi.edu \\ ${ }^{\dagger}$ Crystal IS, Inc., Latham, NY 12110
}

\section{Cite this article as: MRS Internet J. Nitride Semicond. Res. 4S1, G3.76}

\begin{abstract}
High quality, epitaxial growth of $\mathrm{AlN}$ and $\mathrm{Al}_{\mathrm{x}} \mathrm{Ga}_{1-\mathrm{x}} \mathrm{N}$ by OMVPE has been demonstrated on single-crystal AIN substrates. Here we report characterization of epitaxial layers on an a-face AlN substrate using Rutherford Backscattering/ion channeling, atomic force microscopy (AFM), $\mathrm{X}$-ray rocking curves, and preliminary electrical characterization. Ion channeling along the $[10 \overline{1} 0]$ axis gives a channeling minimum yield of $1.5 \%$ indicating a very high quality epitaxial layer.
\end{abstract}

\section{INTRODUCTION}

While III-nitride epitaxy offers great potential for optoelectronic, high temperature and high power devices, the common use of sapphire has many disadvantages. The use of single crystal III-nitride substrates should allow improved epitaxial growth, improved thermal and chemical compatibility, as well as improved thermal conductivity.

We have succeeded in growing single crystals of AlN exceeding $1 \mathrm{~cm}$ in length and $0.5 \mathrm{~cm}$ in diameter using the technique of sublimation and recondensation [1]. Substrates of AlN have been cut from these single crystals boules with either the $(11 \overline{2} 0)$ (a-face) or the (0001) (c-face) orientation. Here we report preliminary results from the growth of $\mathrm{AlN}$ and $\mathrm{Al}_{\mathrm{x}} \mathrm{Ga}_{1-\mathrm{x}} \mathrm{N}$ layers on the a-face substrates.

\section{GROWTH PROCEDURES}

All growths were carried out in an rf-heated, hot-wall, horizontal reactor [2]. The growth temperature was $1100^{\circ} \mathrm{C}$, while the growth pressure was 100 torr. Trimethylaluminum (TMA), trimethylgallium (TMG) and ammonia $\left(\mathrm{NH}_{3}\right)$ were used as the source materials, and the carrier gas was hydrogen. An AlN substrate and a c-plane sapphire substrate were placed side by side to compare epitaxial quality and calibrate the growth rate. After a chemical clean and prior to the epitaxial growth, the substrates were thermally treated at $1100{ }^{\circ} \mathrm{C}$ under $2 \mathrm{slm}$ of hydrogen flow for $5 \mathrm{~min}$ and under a mixed stream of $1 \mathrm{slm}$ ammonia and $2 \mathrm{slm}$ hydrogen for $10 \mathrm{~min}$. After this treatment, the flow rates of $\mathrm{H}_{2}$ and $\mathrm{NH}_{3}$ were adjusted to $3 \mathrm{slm}$ and $2 \mathrm{slm}$ respectively, and then TMA (for AIN growth) or a combination of TMA and TMG (for alloy growth) was switched into reactor. In all cases, the flow rate of TMA was $30 \mathrm{sccm}$.

Under these conditions, the AlN growth rate was about $0.5 \mu \mathrm{m} /$ hour (for the sapphire substrate) as determined by FTIR measurements. Typical growth times were about 1.5 hours. The 50\% alloy discussed below was achieved with $3 \mathrm{sccm}$ and $30 \mathrm{sccm}$ flow rates of TMG and 
TMA, respectively. Doping was accomplished by using $11.1 \mathrm{ppm}$ silane in a hydrogen carrier gas.

\section{CHARACTERIZATION AND ANALYSIS}

In Fig. 1, an AFM image of an AIN substrate is shown prior to epitaxial growth. This particular substrate was cut so as to expose the $(11 \overline{2} 0)$ plane of atoms (the a-face) and was misoriented by less than $1^{\circ}$. It can be seen that substrate surface is nearly atomically flat. Examination of the substrate over a wider area indicates that all evidence of mechanical damage (scratches, etc.) has been removed unlike prior work [3] where micro scratches were observed on the substrate surface after just a mechanical polish. We do observe pit-like defects which may be associated with dislocations intersecting the surface but their origin has not been convincingly determined at this time. Their density is approximately $3 \times 10^{3} \mathrm{~cm}^{-2}$.

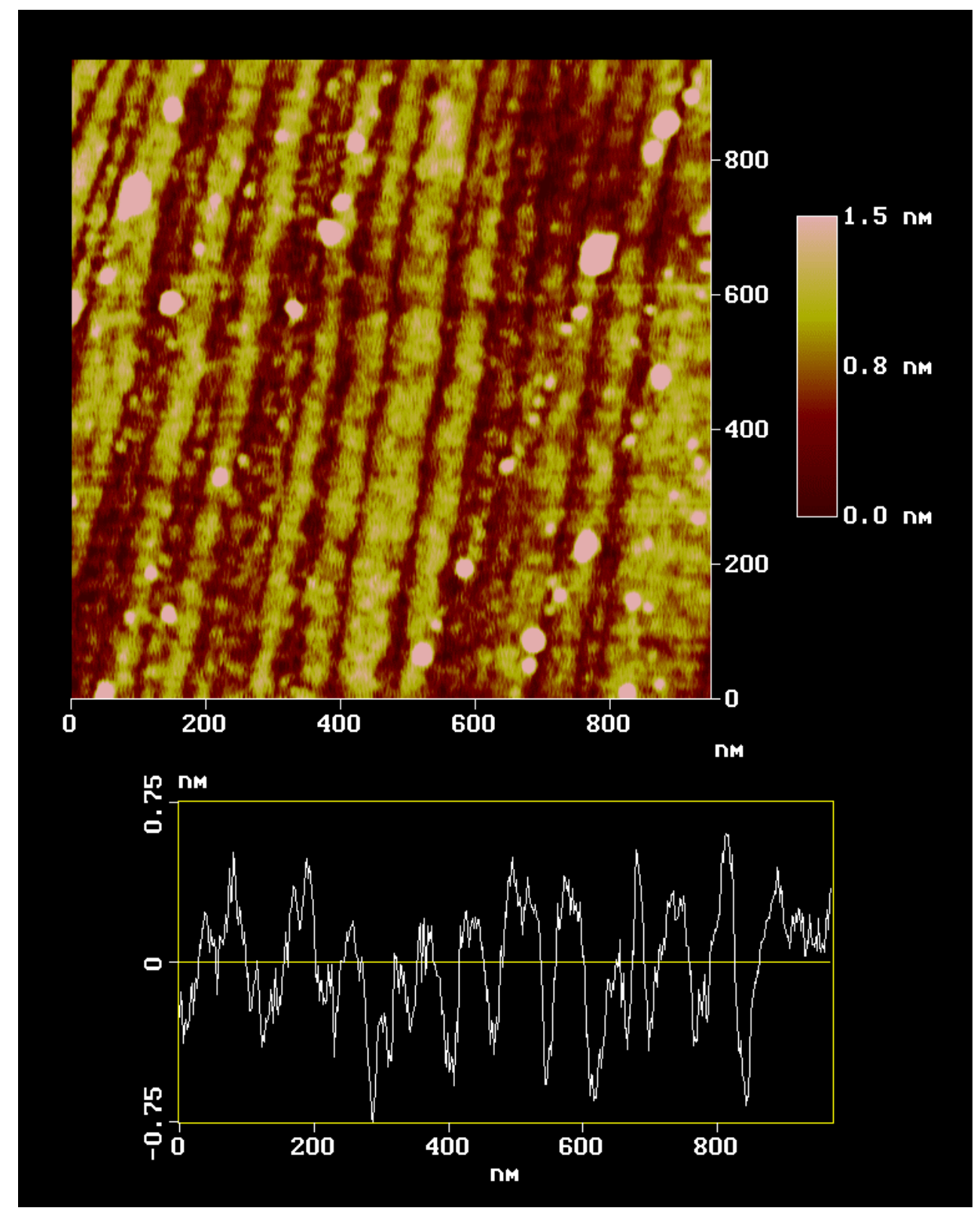

Fig. 1: An AFM image of the bare AlN substrate prior to growth. 
In Fig. 2, an AFM image of a 0.7- $\mu \mathrm{m}$-thick AlN epitaxial layer, grown on a slightly vicinal AlN substrate, is shown. Atomic steps seem to have organized into semi-regular arrays during growth giving rise to a grating effect across the surface. The height of the step bunches is approximately $4 \mathrm{~nm}$. The density of defects across the surface, observed with AFM, increased by approximately 1 order of magnitude from the clean substrate. This increase includes the appearance of short line-like defects that were not observed on the original substrate. The origin of these defects is still being investigated.

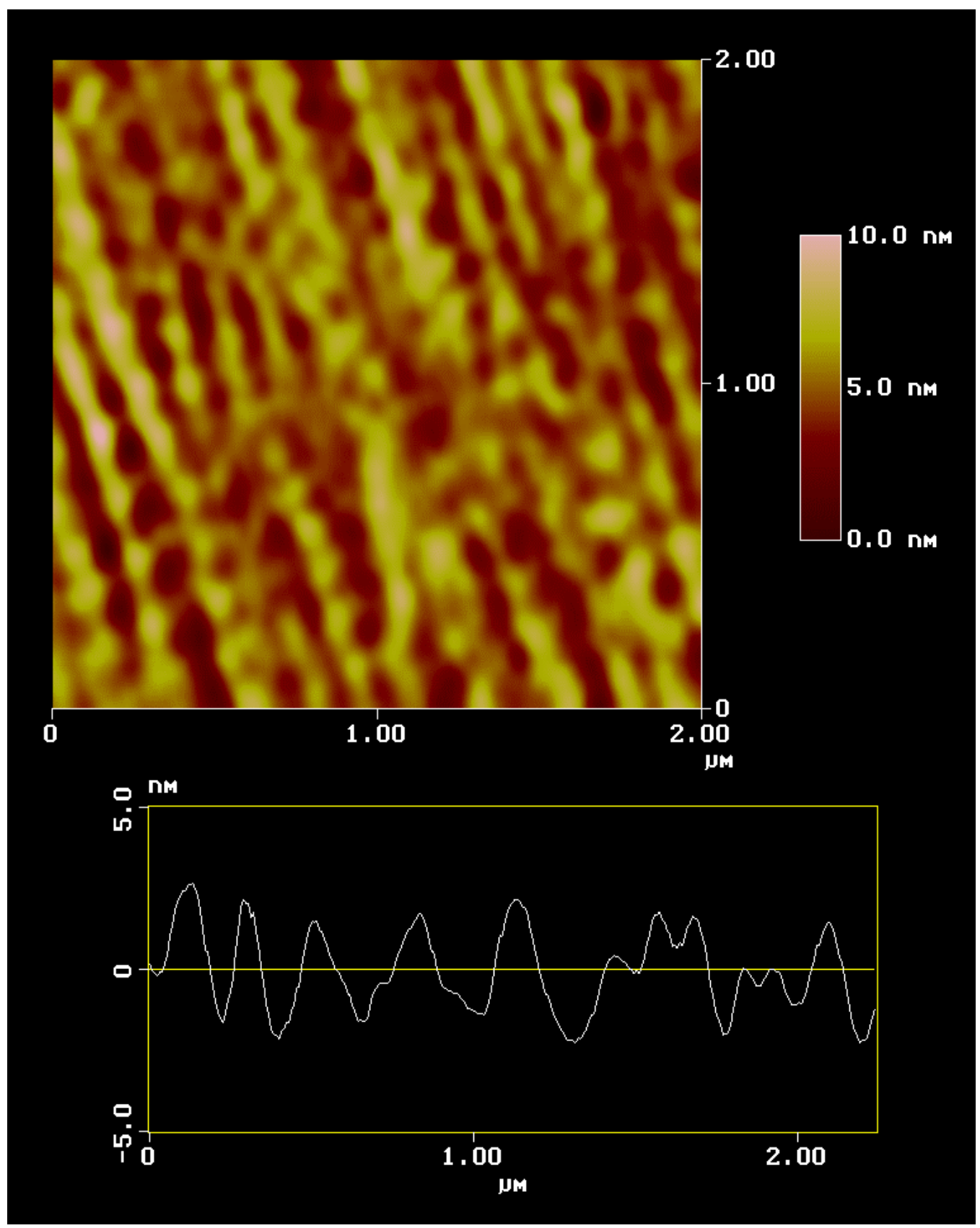

Fig. 2: An AFM image of a 0.7- $\mu$ m-thick epitaxial AlN layer grown on the a-face of an AlN substrate. 
We have also performed AFM characterization of the surface of a 1- $\mu$ m-thick epitaxial film of $\mathrm{Al}_{.5} \mathrm{Ga}_{.5} \mathrm{~N}$. This film showed a much rougher surface morphology even though the epitaxial quality as determined by x-ray diffraction and ion channeling was very good as discussed below. The surface was found to have many mounds on the surface with approximately $30^{\circ}$ facet angles. Of course, it should also be noted that the growth process has not yet been optimized for growth of $\mathrm{Al}_{\mathrm{x}} \mathrm{Ga}_{1-\mathrm{x}} \mathrm{N}$ alloy layers.

Rutherford backscattering/ion channeling measurements were used to determine the crystal quality of the original substrate, the epitaxial AlN layer and the epitaxial $\mathrm{Al}_{.5} \mathrm{Ga}_{5} \mathrm{~N}$ layer. The results from the later two layers are shown in Figs. 3 and 4. These measurements were performed at the SUNY-Albany Dynamatron accelerator with $2 \mathrm{MeV} \mathrm{He}^{4}$ ions. The minimum yield was measured along the [10 10$]$ axis, which is perpendicular to the $(11 \overline{2} 0)$ surface plane of this substrate. We obtained a channeling minimum yield $\chi_{\min }$ of $1.5 \%$ for both the AlN substrate and for the AlN epitaxial layer. The $\chi_{\min }$ is the ratio of the backscattering yield along the crystallographic axis compared to the scattering yield along a random direction and a value of $1.5 \%$ indicates excellent crystal quality (see, for example, ref. 4 where a $\chi_{\min }$ of $2.1 \%$ was measured on a high quality, $3-\mu \mathrm{m}$-thick GaN layer grown under optimal conditions on sapphire). The $\chi_{\text {min }}$ measured for the $1-\mu$ m-thick $\mathrm{Al}_{.5} \mathrm{Ga}_{.5} \mathrm{~N}$ layer was $2.2 \%$, which is still excellent even though the growth parameters were not optimized as pointed out above.

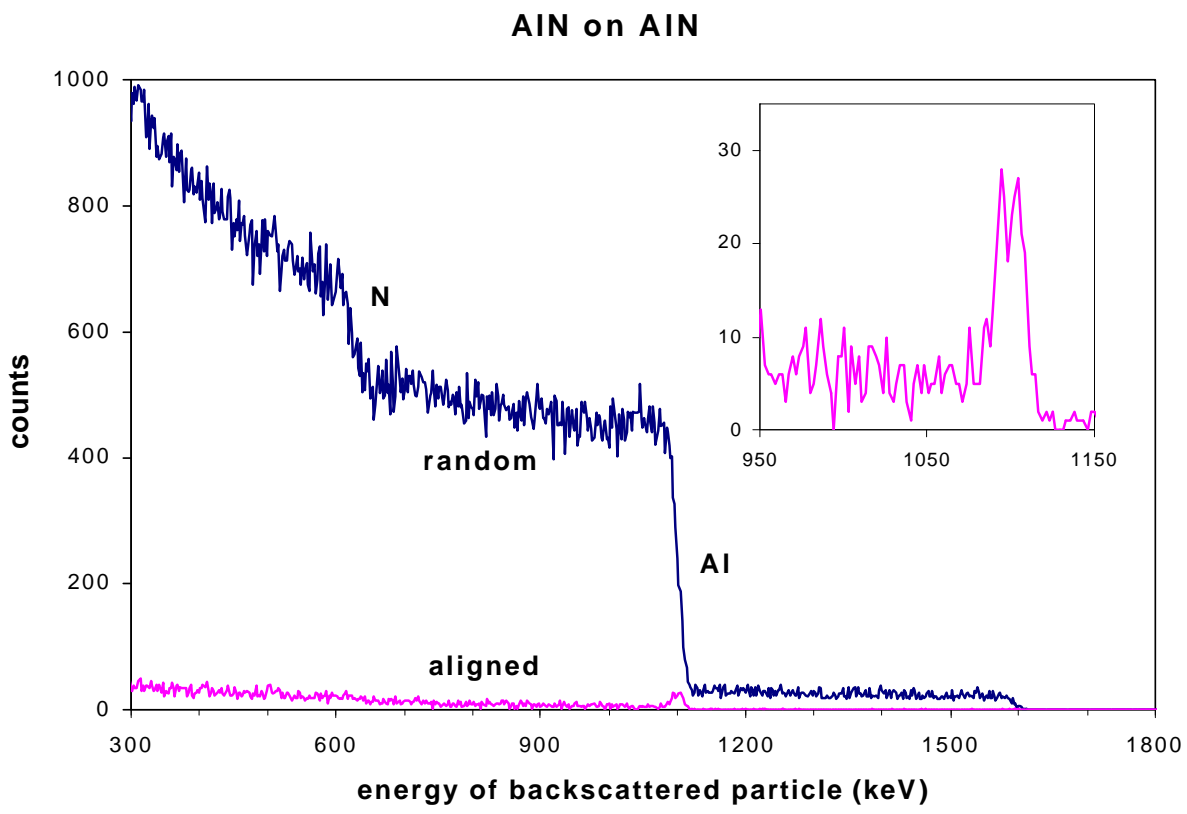

Fig. 3: RBS spectra measured for a random direction and along the [10 $\overline{1} 0]$ axis for a $0.7-\mu \mathrm{m}-$ thick AlN layer grown on the a-face of an AlN substrate. The inset shows a blow-up of the Al surface peak.

Note also in Fig. 3 that some Ga contamination is seen in the epitaxial film. The Ga concentration is approximately $1 \%$ and helps to serve as a marker for the epitaxial AIN film. The ion channeling minimum yield on the AlN/sapphire layer grown under identical conditions was $40 \%$.

The insets in Figs. 3 and 4 show the onset of the $\mathrm{Al}$ and the Ga peaks, respectively. In Fig. 3 , the surface peak is due to the scattering of the He ions by $\mathrm{Al}$ ions on the surface prior to the He ions starting to channel in the crystal. In Fig. 4, it is interesting to note that the Ga surface peak is nearly missing in spite of the fact that the alloy was grown under constant TMA and 
TMG flux. This suggests that the surface layer is depleted of $\mathrm{Ga}$ and suggests that some surface reconstruction may have occurred which preferentially put $\mathrm{Al}$ on the surface. Another possibility is that the epitaxial layer preferentially lost Ga during the cool down phase after growth.

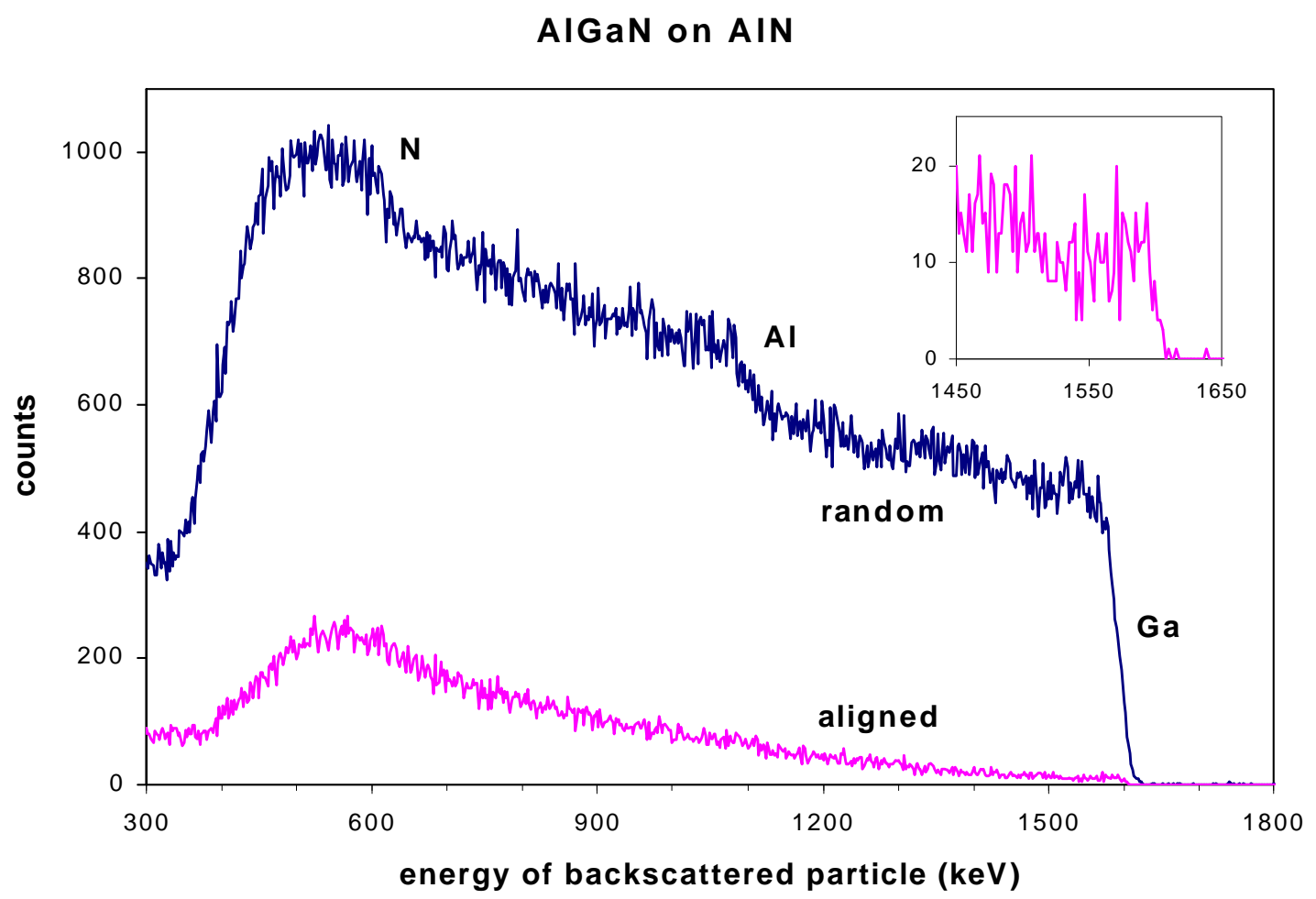

Fig. 4: RBS spectra measured for a random direction and along the [10 $\overline{1} 0]$ axis for a $1-\mu \mathrm{m}$-thick $\mathrm{Al}_{.5} \mathrm{Ga}_{5} \mathrm{~N}$ layer grown on the a-face of an AlN substrate. The inset shows a blow-up of the nearly absent, Ga surface peak.

Double crystal, $\mathrm{x}$-ray diffraction (Bede diffractometer, $\mathrm{Cu} \mathrm{K}_{\alpha}$ ) radiation was also used to characterize the quality of the epitaxial layers. A GaSb (004) reflection was used to monochromatize the $\mathrm{x}$-rays and the $(11 \overline{2} 0)$ reflection was scanned. The epitaxial AlN/AlN substrate was shown to consist of several crystal grains, with small angles (of the order of 50-100 arcsecs) between them. The relative peak amplitudes could be varied by moving the x-ray beam across the surface. This observation coincided with optical observations that indicated possible grain boundaries across the substrate surface. The largest grain was approximately $3 \mathrm{~mm} \times 5 \mathrm{~mm}$. A rocking curve, FWHM of the epitaxial AlN layer was approximately 250 arc sec. when all the crystal grains were considered simultaneously. However, the FWHM of individual grains appeared to be less than 100 arc sec.

The $\mathrm{Al}_{.5} \mathrm{Ga}_{5} \mathrm{~N}$ alloy was doped with $\mathrm{Si}$ as described above using a silane/hydrogen flow rate of $3 \mathrm{sccm}$. The $1-\mu \mathrm{m}$-thick film exhibited a resistivity of approximately $20 \Omega$-cm. Hall measurements were made using In dots that allowed good Ohmic contacts to be made to the epitaxial layer. The concentration of carriers was approximately $10^{17} \mathrm{~cm}^{-3}$ with a mobility of $\sim 10 \mathrm{~cm}^{2} / \mathrm{V}$-s. Generally groups have found that doping of $\mathrm{Al}_{\mathrm{x}} \mathrm{Ga}_{1-\mathrm{x}} \mathrm{N}$ alloys is difficult at high $\mathrm{Al}$ fraction $[5,6]$ probably due to the inferior material quality. Our results here are in good agreement with Bemser et al. [7] for high concentration $\mathrm{Al}$ alloys grown on $6 \mathrm{H}-\mathrm{SiC}(0001)$ substrates. 


\section{CONCLUSION}

We have demonstrated that a-face AlN substrates can be prepared for excellent homoepitaxial growth of AIN. In addition, we have demonstrated high quality alloy growth of $\mathrm{Al}_{.5} \mathrm{Ga}_{.5} \mathrm{~N}$ on these substrates that showed excellent electrical conductivity even though the growth conditions were not optimized. The AlN substrates offer an excellent opportunity to achieve high quality epitaxial growth of AlGaN alloys on a high thermal conductivity, electrically insulating substrate with minimal thermal expansion mismatch.

\section{ACKNOWLEDGEMENTS}

The contributions of Jonathan Ward in substrate preparation are hereby gratefully acknowledged. This work was partially supported by the Ballistic Missile Defense Organization (BMDO) and ONR. The support and advice of Dr. C.E.C. Wood at ONR was greatly appreciated. In addition, Crystal IS received support from BMDO and was managed by the Materials Directorate of the Air Force Research Laboratory, USAF, Wright-Patterson AFB.

\section{REFERENCES}

1. The growth procedure is described in: G.A. Slack and T. McNelly, J. Cryst. Growth 34, 263 (1976) and 42560 (1977).

2. H. Lu and I. Bhat, Gallium Nitride and Related Materials, MRS Proc. Vol. 395, ed. F.A. Ponce, R. D. Dupuis, S. Nakamura, and J.A. Edmond (Pittsburgh, Mat. Res. Soc., 1996) p. 497.

3. H. Lu, I. Bhat, B.-C. Lee, G. Slack, and L. Schowalter, Nitride Semiconductors, MRS Proc. Vol. 482, ed. R.A. Ponce, S.P. DenBaars, B.K. Meyer, S. Nakamura, and S.Strite (Pittsburgh, Mat. Res. Soc., 1998) p. 277.

4. H. Kobayashi and W.M. Gibson, Appl. Phys. Lett. 73, 1406 (1998).

5. X. Zhang, P. Kung, A. Saxler, D. Walker, T. C. Wang, and M. Razeghi, Appl. Phys. Lett. 67, 1745 (1995).

6. J. M. Redwing, J. S. Flynn, M. A. Tischler, W. Mitchel, and A. Saxler, Gallium Nitride and Related Materials, MRS Proc. Vol. 395, ed. F.A. Ponce, R. D. Dupuis, S. Nakamura, and J.A. Edmond (Pittsburgh, Mat. Res. Soc., 1996) p. 201.

7. M.D. Bremser, W.G. Perry, O.H. Nam, D.P. Griffis, R. Losing, D.A. Ricks, and R.F. Davis, J. Electronic Materials, 27, 229 (1998). 